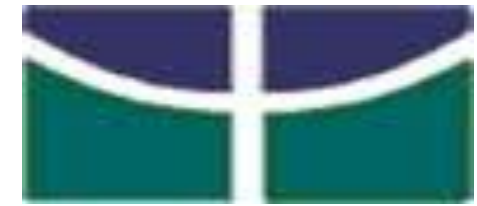

UNIVERSIDADE DE BRASÍLIA

Faculdade de Educação - UAB/UnB/ MEC/SECAD

Curso de Especialização em Educação na Diversidade e Cidadania, com Ênfase em EJA

Maria veras coelho

leda Soares Pinto

Auricéia C. do Nascimento Brígida

JOVEM/ADULTO TRABALHADOR E/OU EMPREENDEDOR NA EJA

BRASILIA, DF

JULHO/ 2010 


\title{
JOVEM/ADULTO TRABALHADOR E/OU EMPREENDEDOR NA EJA
}

\author{
Maria Veras Coelho \\ leda Soares Pinto \\ Auricéia C. do Nascimento Brígida \\ Professora Orientadora: Maria Clarisse Vieira. \\ Tutor Orientador: Marco Aurélio Braga.
}

Projeto de Intervenção Local - PIL de conclusão de curso, do Departamento de Educação/FE/UAB/SECAD, da Universidade de Brasília, apresentado como requisito à obtenção do Título de Especialista em Educação na Diversidade e Cidadania, com Ênfase na Educação de Jovens e Adultos.

BRASILIA, DF/ JULHO/ 2010

UNIVERSIDADE DE BRASÍLIA 


\section{O JOVEM/ADULTO TRABALHADOR E/OU EMPREENDEDOR NA EJA}

Projeto de Intervenção Local - PIL. Trabalho de conclusão do Curso Especialização em Educação na Diversidade e Cidadania, com Ênfase em EJA, como parte dos requisitos necessários para obtenção do grau de Especialista na Educação de Jovens e Adultos.

Professor Orientador

Tutor Orientador

Avaliador Externo

BRASÍLIA - DF, Julho/2010 


$$
\begin{gathered}
\text { aí } \\
\text { de } \\
\text { nós } \\
\text { se } \\
\text { por } \\
\text { culpa } \\
\text { nossa } \\
\text { semente } \\
\text { morrer } \\
\text { semente } \\
\text { !n! } \\
\text { Atodos os Tutores } \\
\text { Bravos } \\
\text { Sonhadores } \\
\text { pela sua Fé } \\
\text { peloseu Empenho... } \\
\text { pela Democracía } \\
\text { pelo Conhecimento } \\
\text { pela Educação a Distâncía } \\
\text { Dedico! }
\end{gathered}
$$


Não diga que a canção

Está perdida

Tenha em fé em Deus

Tenha fé na vida

Tente outra vez!...

Beba! (Beba!)

Pois a água viva

Ainda tá na fonte

(Tente outra vez!)

Você tem dois pés

Para cruzar a ponte

Nada acabou!

Não! Não! Não!...

Oh! Oh! Oh! Oh!

Tente!

Levante sua mão sedenta

E recomece a andar

Não pense

Que a cabeça agüenta

Se você parar

Não! Não! Não!

Não! Não! Não!...

Há uma voz que canta

Uma voz que dança

Uma voz que gira

(Gira!)

Bailando no ar

Uh! Uh! Uh!...

Queira! (Queira!)

Basta ser sincero

E desejar profundo

Você será capaz

De sacudir o mundo

Vai!

Tente outra vez!

Humrum!...

Tente! (Tente!)

E não diga

Que a vitória está perdida

Se é de batalhas

Que se vive a vida

Han!

Tente outra vez!...

Raul Seixas 


\section{SUMÁRIO}

INTRODUÇÃO

1. DADOS DE IDENTIFICAÇÃO DOS PROPONENTES ..............................................13

1.1 MARIA VERAS COELHO ...................................................................................13

1.1.1 Informações para contato...................................................................................13

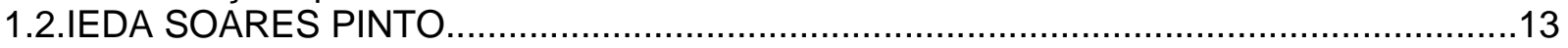

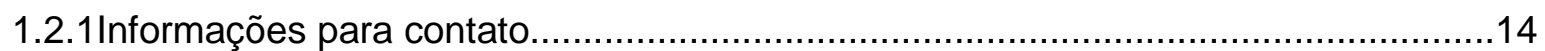

1.2 AURICÉIA CRISTINA DO NASCIMENTO BRÍGIDA ............................................. 14

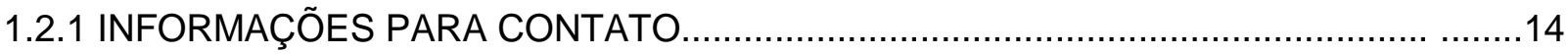

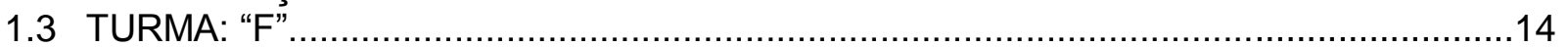

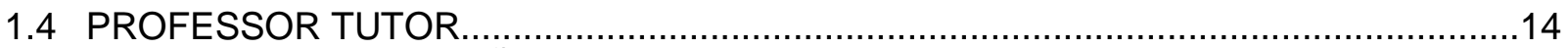

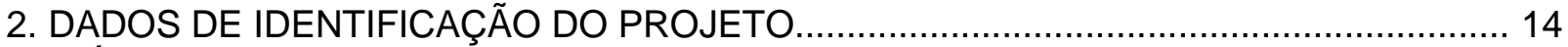

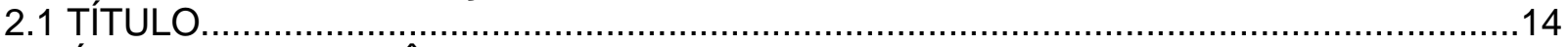

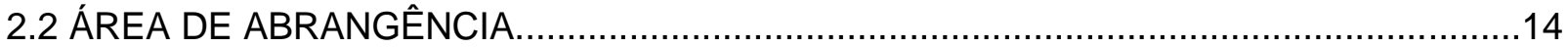

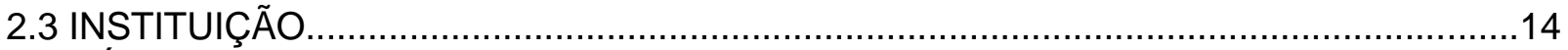

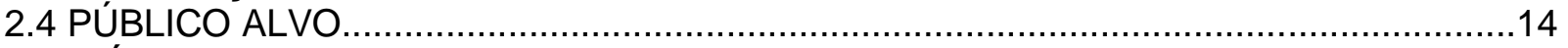

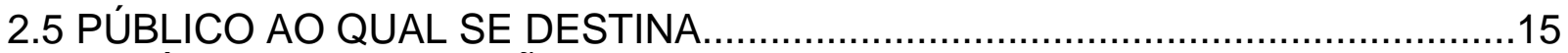

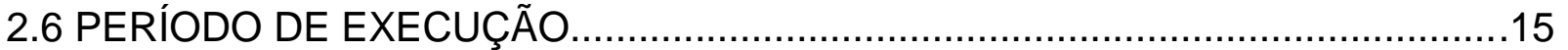

3. O CONTEXTO INSTITUCIONAL - MARCO SITUACIONAL ..............................15

3.1 CARACTERIZAÇÃO/IDENTIFICAÇÃO DO PROBLEMA...............................16

4. JUSTIFICATIVA: MARCO CONCEITUAL - FUNDAMENTAÇÃO TEÓRICA...........17

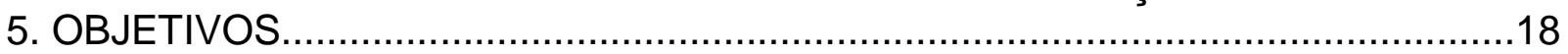

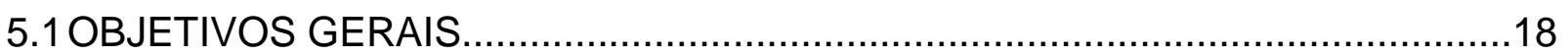

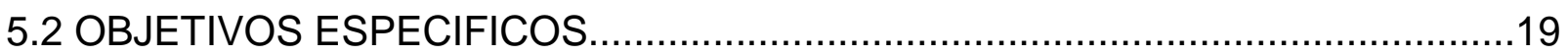

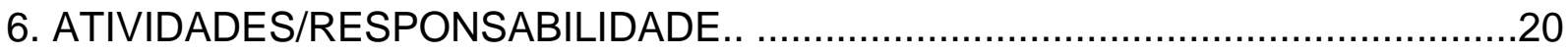

7. CRONOGRAMA

8. PARCEIROS

9. ORÇAMENTO

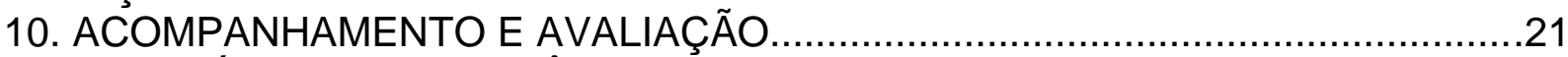

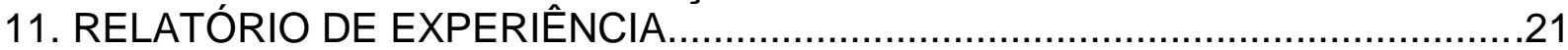

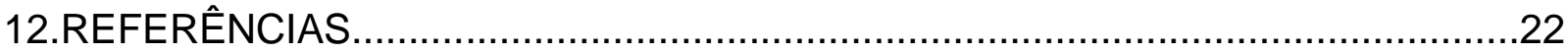

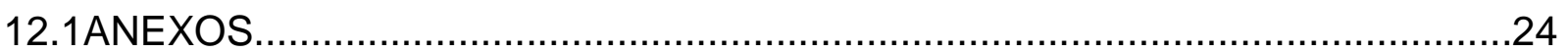


Universidade de Brasília - UnB

Faculdade de Educação - FE

Universidade Aberta do Brasil - UAB

Especialização em

Educação na Diversidade e Cidadania,

Com Ênfase na Educação de Jovens e Adultos

Projeto de Intervenção Local - PIL

Propositoras: Maria Veras Coelho, leda Soares Pinto e Auricéia C. do N. Brígida

\begin{abstract}
RESUMO
Este trabalho se refere a um projeto de intervenção local, que tem como objeto de estudo a implementação da modalidade Educação Profissional integrada à Educação de Jovens e Adultos (EJA) em uma escola da secretaria de educação do Distrito Federal. Objetiva-se nesse projeto, criar uma articulação entre formação para o trabalho e a elevação de escolaridade, bem como refletir sobre as condições de implementação do curso, a partir da realidade da política educacional na cidade de Ceilândia. Em função disso, o referencial é baseado nas formulações teorias de Marx e de outros teóricos tais como Gramsci, Manacorda, Pistrak, Freire, para os quais a categoria trabalho é o alicerce para pensar a educação. Optou-se pela pesquisa qualitativa feita por meio de estudo de caso, utilizando-se das ferramentas metodológicas: questionário, entrevistas, redações e análise documental/territorial. Ao presente projeto interessa discutir acerca das primeiras análises sobre os documentos oficiais, identificando e traçando os princípios elencados pelos gestores públicos e a trajetória percorrida pela referida cidade no que se refere ao atendimento do direito à educação das pessoas jovens e adultas. Acreditamos que há uma grande contribuição dessa experiência para o campo da EJA e da Educação Profissional no âmbito de consolidação de uma política educacional com vista a torna-se, realmente, política de estado.
\end{abstract}

Palavras chaves: EJA, Profissionalizante, Trabalhador, Empreendedor, Jovem/Adulto. 
LISTA DE ABREVIATURAS

\begin{tabular}{|l|l|}
\hline CBC & Currículos Básicos Nacionais \\
\hline CEF & Centro de Ensino Fundamental \\
\hline CNE & Conselho Nacional de Educação \\
\hline EJA & Educação de Jovens e Adultos \\
\hline ENCCEJA & Adultos \\
\hline GDF & Governo do Distrito Federal \\
\hline IFB & Instituto Federal de Brasília \\
\hline LDB & Lei de Diretrizes e Bases \\
\hline ONG & Organização Não Governamental \\
\hline PCN & Parâmetros Curriculares Nacionais \\
\hline PIL & Projeto de Intervenção Local \\
\hline PPP & Projeto Político Pedagógico \\
\hline PROEJA & $\begin{array}{l}\text { Programa Nacional de Integração da Educação com a Educação } \\
\text { Básica na Modalidade de Educação de Jovens e Adultos }\end{array}$ \\
\hline SEBRAE & Serviço Brasileiro de Apoio os Micro e Pequenas Empresas \\
\hline SENAI & Serviço Nacional de Aprendizagem Industrial \\
\hline SENAC & Serviço Nacional de Aprendizagem Comercial \\
\hline UNESCO & Organização das Nações Unidas Para Educação, a Ciência e a \\
\hline
\end{tabular}




\section{INTRODUÇÃO}

O presente projeto intitulado "O JOVEM/ADULTO TRABALHADOR E/OU EMPREENDEDOR NA EJA", cujo objetivo é sensibilizar o aluno para a formação de si mesmo por meio de discussões sobre o seu papel social, em uma sociedade globalizada, competitiva e desenvolver uma investigação acerca de quais são os fatores determinantes de sucesso e/ou de fracasso na implementação de uma proposta educacional de Educação de Jovens e Adultos (EJA) integrada à Qualificação Profissional no DF/Cidade estrutural.

A Educação de Jovens e Adultos EJA é uma temática que se apresenta atualmente no Distrito Federal como um campo de estudo bastante explorado na academia com o desenvolvimento de muitas pesquisas. Esses estudos visam, dentre outros propósitos, superar concepções tradicionais encontradas na implementação dessa modalidade enquanto práticas educativas e políticas educacionais emancipadoras.

Essas questões e outras tantas estão suscitadas em vários espaços que promovem a discussão acerca do direito à educação e como esse direito tem ganhado amplitude tanto nas pesquisas propostas no campo acadêmico quanto nas discussões em espaços sociais e políticos. Dessa forma, em se tratando de trabalhar os novos paradigmas da EJA, estamos dissertando sobre a luta por uma educação para todos que abrange e se efetua, também, não só por estratégias do poder público, mas ainda, por meio de outros sujeitos e instituições atuantes promovendo ações coletivas em prol de uma educação de qualidade.

Outro aspecto importante é lembrar que, para além do princípio do direito à escolaridade, e conseqüentemente o aumento dos anos de estudo, caminhamos também para agregar à educação uma concepção de aprendizagem ao longo da vida, sem idade "certa" para aprender, princípio esse referendado pela Declaração de Hamburgo (1997) na qual está exposta que os objetivos da educação de jovens e adultos, vistos como um processo de longo prazo desenvolve a autonomia e o senso de responsabilidade das pessoas e das comunidades, fortalecendo a capacidade de lidar com as transformações que ocorrem na economia, na cultura e na sociedade como um todo; promove a coexistência, a tolerância e a participação criativa e crítica dos cidadãos em suas comunidades, permitindo assim que as pessoas controlem seus destinos e enfrentem os desafios que se encontram à frente. Declaração de Hamburgo (1997).

A vinculação entre educação e trabalho torna-se, assim, uma referência primordial. No que diz respeito à educação profissional, a LDB esclarece que: A educação profissional, integrada às diferentes formas de educação, ao trabalho, à ciência e à tecnologia, conduz ao permanente desenvolvimento de aptidões para a vida produtiva. (BRASIL, 1996, Art. 39). 
Isto significa que não se pode tratar a formação como algo exclusivamente do mundo do trabalho ou do mundo da educação. Trata-se de percebê-la como um ponto de intersecção, para o qual devem confluir diversas abordagens e contribuições, entre elas a dos sujeitos trabalhadores.

\begin{abstract}
Nessa intersecção, que compreende múltiplas dimensões, a qualificação nunca é apenas "profissional" (dimensão técnica), mas sempre "social" (dimensão sociolaboral). Pode-se falar, portanto, em qualificação social e profissional para denominar as ações de formação voltadas para uma inserção autônoma e solidária no mundo do trabalho. A qualificação social e profissional permite a inserção e atuação cidadã no mundo do trabalho, com efetivo impacto para a vida e o trabalho das pessoas (BRASIL, 2003, p. 24). Para isso, faz-se necessário no decorrer do processo formativo "a promoção de atividades político- pedagógicas baseadas em metodologias inovadoras dentro de um pensamento emancipatório de inclusão, tendo o trabalho como princípio educativo; o direito ao trabalho como um valor estruturante da cidadania; a qualificação como uma política de inclusão social e um suporte indispensável do desenvolvimento sustentável, a associação entre a participação social e a pesquisa como elementos articulados na construção desta política e na melhoria da base de informação sobre a relação trabalhoeducação-desenvolvimento. Isso possibilita a melhoria das condições de trabalho e da qualidade social de vida da população" (BRASIL, 2005, p. 20 21). (proeja, documento base,2007)
\end{abstract}

Embora diversos estudos estejam discutindo vários aspectos ligados à EJA, percebemos uma lacuna de conhecimentos sistematizados que procuram fazer uma interlocução entre a Educação profissional e a Educação formal. Na investigação, pretende-se refletir sobre a apreensão ou não da concepção do conceito da categoria trabalho como princípio educativo por parte dos propositores do projeto, ou seja, se os gestores públicos propõem uma proposta educativa na qual se analisa a positividade do trabalho enquanto possibilidade de formação humana, na perspectiva do trabalho ainda como um direito do trabalhador. No sentido de buscar uma educação que se torne um meio de instrumentalizar os estudantes trabalhadores, preparando-os para acompanhar as transformações do mundo do trabalho.

Essa política concebe a educação como direito de todos e processo contínuo que se desenvolve ao longo da vida. Nesse sentido, é essencial considerar as especificidades da educação de jovens e adultos. É necessário, também, estabelecer a relação entre educação profissional, ensino médio e EJA, trançando os fios que entrelaçam a perspectiva de pensar, de forma integrada, um projeto educativo, para além de segmentações e superposições que tão pouco revelam as possibilidades de ver mais complexamente a realidade e, por esse ponto de vista, pensar também a intervenção pedagógica.

A concepção de EJA, na perspectiva de uma educação continuada ao longo da vida, foi enfatizada no Art. 3ำ da Declaração de Hamburgo, fruto da $V$ CONFINTEA realizada em 1997, ao afirmar que: 
A educação de adultos engloba todo o processo de aprendizagem formal ou informal, onde pessoas consideradas "adultas" pela sociedade desenvolvem suas habilidades, enriquecem seu conhecimento e aperfeiçoam suas qualificações técnicas e profissionais, direcionando-as para a satisfação de suas necessidades e as de sua sociedade. A educação de adultos inclui a educação formal, a educação não-formal e o espectro da aprendizagem informal e incidental disponível numa sociedade multicultural, onde os estudos baseados na teoria e na prática devem ser reconhecidos.

(In: IRELAND, MACHADO, PAIVA, 2004, p. 42).

A EJA é entendida aqui, então, tanto como modalidade de ensino como estratégia de formação continuada. As funções reparadoras e equalizadoras, por meio das quais o Parecer CNE/CEB no. 11/2000 atribui o caráter de fazer cumprir o dever do Estado para assegurar o direito de todos à educação, reduzindo a desigualdade entre os que a tiveram e aqueles aos quais o acesso foi interditado, associa-se à terceira função - a qualificadora. Esta função, segundo o Parecer, revela o verdadeiro sentido da EJA, compreendida na perspectiva da formação para o exercício pleno da cidadania, por meio do desenvolvimento do pensamento crítico e autônomo de cidadãos participativos, conscientes de seus direitos sociais e de sua compreensão/ inserção no mundo do trabalho, entendido como elemento fundamental ao processo de omnização de homens e mulheres e de produção cultural.

O grande desafio dessa política é a construção de uma identidade própria para novos espaços educativos, inclusive de uma escola de/ para jovens e adultos. Em função das especificidades dos sujeitos da EJA (jovens, adultos, terceira idade, trabalhadores, população do campo, mulheres, negros, pessoas com necessidades educacionais especiais, dentre outros), a superação das estruturas rígidas de tempo e espaço presentes na escola (ARROYO, 2004) é um aspecto fundamental.

Isto remete ao reconhecimento dos espaços de produção de saberes na sociedade, muitos deles interditados aos jovens e adultos para a fruição e acesso, como, por exemplo, os que possibilitam a vivência com bens culturais produzidos historicamente - disponíveis em museus, teatros, bibliotecas, cinemas, exposições de arte. "Se esta precisa ser uma referência para o currículo do ensino médio com educação profissional, exige também reconhecer formas e manifestações culturais não-hegemônicas produzidas por grupos de menor prestígio social e, quase sempre, negadas e invisibilizadas na sociedade e na escola." (PROEJA, Documento base, Brasília, agosto 2007).

Lembramos que este Projeto exige mais do que uma leitura individual por parte dos educadores; pressupõe uma reflexão coletiva para que se possa fazer a relação com a realidade local e, ainda, que toda a intervenção pedagógica carece de consensos entre educandos e educadores, tanto sobre as estratégias e às opções político-pedagógicas que podem ser viabilizadas na Educação de Jovens e Adultos. 
Para Arroyo (2001), uma vez que, os vínculos entre educação, escola e trabalho situam-se numa perspectiva mais ampla, tendo em vista a constituição histórica do ser humano, de sua formação intelectual e moral, sua autonomia e liberdade individual e coletiva, sua emancipação. O trabalho contempla, assim, uma forma de produção da vida material a partir do qual se produzem distintos sistemas de significação. Sendo assim, os educandos da EJA tendem a buscar cursos técnicos, já que esses cursos geralmente são de curta duração, baixo custo e ainda atendem a necessidade do mercado. Como são trabalhadores, apresentam pouca disponibilidade de tempo para cursar uma faculdade, deste modo, os cursos técnicos surgem como uma opção viável. Assim, é importante que as políticas públicas para o EJA atendam também a necessidade de formação profissional.

A ideia de que "a escolha de uma profissão é algo que vem angustiando milhares de jovens que, todos os anos, são levados a tomar uma decisão que poderá afetar sua vida, ou pelo menos, boa parte dela." (Nascimento, 2009). Mostra a grande importância de se pensar em programas que visem orientar profissionalmente esses indivíduos da EJA. São poucos os jovens que conseguem elaborar a decisão da escolha profissional de forma madura e consciente, onde em conseqüência muitos acabam abandonando seus projetos. O jovem, dentro da escola, deve ter a possibilidade de se confrontar com alguns aspectos da vida profissional que poderá ou não seguir; para tanto, parte-se do pressuposto levantado por Levenfus(1997) de que, no trabalho da escolha da profissão, a sensibilização para o momento vivido pelo adolescente dentro desse contexto social mais amplo tem de ser levado em consideração.

É sabido que há interesse dos educando da EJA em continuar seus estudos e superar as dificuldades que a vida lhes apresentou. Existe o desejo de ser um profissional e não apenas um trabalhador. Esse desejo indica a necessidade de políticas públicas que promovam não só a alfabetização dos jovens e adultos, mas também criem programas de desenvolvimento profissional desses indivíduos.

O jovem é sujeito de sua história, ele recebe orientações para toda sua vida, primeiramente é uma oportunidade de profissionalização. Segundo, ele aprende e reflete o conhecimento adquirido valorizando, reconhecendo e aprimorando informações sobre cultura, patrimônio e sítios históricos da cidade. Esse conhecimento ele carrega por toda sua vida. Neste projeto, procuramos oportunizar o direito e as conquistas sociais como patrimônio do jovem cidadão, morador da comunidade na qual vive e trabalha.

A metodologia aplicada leva em consideração o saber acumulado e a experiência dos educandos, fortalecendo a cultura que se expressa nas comunidades. Possibilita o acesso à informação e conhecimento do processo de produção cultural, seus meios e produtos; 
favorece a participação popular no processo decisório. Durante os cursos e oficinas oferece acesso aos bens culturais, desperta interesses e talentos e transforma aptidões em ofícios, através de oficinas de arte e cultura e cursos profissionalizantes da cadeia produtiva da cultura.

O compromisso de oferecer uma Educação Profissional que torna a o trabalho como princípio educativo, princípio este que considera o homem em sua totalidade histórica leva em conta as diferentes contradições que o processo produtivo contemporâneo traz para a formação humana.

Essa nova proposta está fundamentada a partir do direito do cidadão aos saberes sistematizados, da universalização do ensino em nível médio, da escola pública gratuita e de qualidade para todos, a qual considera a diversidade cultural de experiências e vivências de cada sujeito, bem como, a organização coletiva do trabalho escolar. Assim sendo, aponta como princípio primeiro o trabalho, o trabalho como princípio educativo uma vez que é por meio dele que se dá a produção da condição humana e a ação transformadora do mundo, tanto dos homens entre si quanto em relação ao meio em que vivem.

O presente projeto visa à formação de cidadãos-profissionais com entendimento da realidade social, econômica, política e cultural do mundo do trabalho, para nele inserir-se e atuar de forma ética visando à transformação da sociedade em função dos interesses sociais e coletivos.

Para a efetivação dessa política educacional, torna-se necessário o engajamento de todos os envolvidos no processo, a busca do conhecimento necessário para lidar com o novo, bem como a disposição para o aprimoramento constante.

Portanto, para obter êxito na política defendida ao longo deste trabalho, é imprescindível compreender, dentre outros aspectos, que a Educação Profissional Integrada à Educação de Jovens e Adultos tem um público alvo diferenciado que demanda por um corpo docente teórico-metodológico com identidade própria.

\section{DADOS DE IDENTIFICAÇÃO DOS PROPONENTES:}

1.1 MARIA VERAS COELHO

1.1.1 Informações para contato

E-mail: nena.v.coelho@gmail.com

Telefone: 3965-9141, 8136-0137

1.2 IEDA SOARES PINTO

1.2.1 Informações para contato 
E-mail: soaresieda@yahoo.com.br

Telefone: 8603-4719/3397-5734

1.3 AURICÉIA CRISTINA DO NASCIMENTO BRÍGIDA

1.3.1 Informações para contato

E-mail: aurybrigida@hotmail.com

Telefone: 3358-3053, 9157-2466

\subsection{TURMA: "F"}

1.5 PROFESSOR TUTOR: Marco Aurélio Braga.

\section{DADOS DE IDENTIFICAÇÃO DO PROJETO:}

2.1- TÍTULO: O JOVEM/ADULTO TRABALHADOR E/OU EMPREENDEDOR NA EJA

2.2- ÁREA DE ABRANGÊNCIA: Local e/ou regional.

2.3- INSTITUIÇÃO:

NOME: Centro de Ensino fundamental 16

ENDEREÇO: QNL 22 área especial 24 - Taguatinga norte

\section{Instância institucional de decisão:}

- Governo do Distrito Federal

- Secretaria de Estado de Educação do Distrito Federal

- Conselho de Educação do Distrito Federal

- Regional: Diretoria Regional de Ensino de Taguatinga

- Escola - Coordenação Pedagógica e Gestão Escolar.

2.4- PÚBLICO ALVO:

a) Alunos (as);

b) Professores;

c) Diretores;

d) Comunidade.

2.5- PÚBLICO AO QUAL SE DESTINA: 
Atender as escolas que atuam na educação de jovens e adultos do Distrito Federal.

\section{6- PERÍODO DE EXECUÇÃO: indeterminado}

Início (mês/ano): 08/2010

Término: $12 / 2010$

\section{O CONTEXTO INSTITUCIONAL - MARCO SITUACIONAL}

O Centro de Ensino Fundamental 16 está localizado na: QNL, quadra 22 área especial 24, zona urbana. O CEF 16 é uma instituição pública da Secretaria de Estado do DF, modalidades ensino fundamental $5^{a}$ a $8^{a}$ séries (diurno) e EJA - $1^{\circ}$ e $2^{0}$ seguimentos (noturno).

O CEF 16, antiga escola classe 47, situa-se no setor QNL, quadra 22 área especial 24, Zona Urbana, onde os moradores são oriundos das invasões "Boca da Mata", "Chaparral" e "Vila do Maestro", que receberam casas semi-prontas, sem infra- estrutura e saneamento básico.

Diante da formação de um novo espaço territorial urbano, tornou-se necessária a construção de escolas para atender a comunidade que ali se instalava. Assim surgiu a antiga escola classe 47 - hoje CEF 16 - de forma improvisada e com estrutura de lata. Somente em 1996 com a resolução $n^{\circ}$ 5439/96 a Escola Classe 47 torno-se CEF 16, sendo entregue a comunidade em 6/11/1997 com sua estrutura atual.

Atualmente a escola conta com uma estrutura física em boas condições de uso e conservação, com 12 salas de aula, uma sala de Artes, uma de recursos áudios-visuais, uma biblioteca, uma sala para o serviço de Orientação Educacional (SOE), uma sala de coordenação, uma de professores, uma de servidores, uma mecanografia, secretaria, direção, cantina, pátio, quadra de esportes.

O PPP do CEF 16 tem como objetivo principal avaliar os problemas mais significativos (violência, tráfico de drogas, evasão e repetência) e propor as soluções como o apoio de toda a comunidade escolar e sua efetiva participação nesse processo de mudança.

A escola trabalha atualmente com projetos de música, escola aberta, onde é oferecido aulas de informática para a comunidade e alunos, aulas de caratê, dança, fuxico, bordado e um trabalho social-religioso com distribuição de alimentos para a comunidade. Atua no diurno com os projetos ciência em foco, matemática em foco, leio e escrevo o meu futuro e eleitor do futuro.

Os alunos são oriundos de classes sociais de baixa renda, famílias muitas vezes desestruturadas que não conseguem, por vários motivos, um acompanhamento sistemático dos filhos na escola. Ricardo Antunes (1999) lembra que estas mudanças iniciaram a partir 
1973, com o surgimento do regime de acumulação flexível, que se caracteriza pela nova divisão de mercados, desemprego, divisão global do trabalho, capital volátil, fechamento de plantas industriais, reorganização financeira e tecnológica, entre tantas mutações que marcam essa nova fase da produção capitalista. Há também a questão da violência que deixa os alunos inseguros e desestimulados.

Os alunos CEF 16 consideram a escola como sendo importante para as suas vidas, porém em recente pesquisa destacou-se que $43 \%$ nunca reprovou, $28,7 \%$ reprovou uma vez e $18,7 \%$ reprovou duas vezes.

Ao analisar o PPP do CEF 16 percebe-se que a Educação de Jovens e Adultos ficou esquecida pela instituição, pois todos os projetos desenvolvidos estão direcionados aos alunos do diurno. A EJA é citada apenas pelo uso da estrutura física da instituição.

\subsection{CARACTERIZAÇÃO/IDENTIFICAÇÃO DO PROBLEMA:}

O Projeto O Jovem Empreendedor na EJA foi pensado após a constatação feita nas escolas de que os alunos da EJA apresentam grande desmotivação em dar continuidade aos estudos, pois a maioria deles já está inserida no mercado de trabalho e abre mão, facilmente, de sua formação escolar em função de suas necessidades imediatas de sobrevivência. Com o intuito de fazer com que nosso aluno modifique o olhar sobre si mesmo e amplie a sua perspectiva de futuro, de forma consciente e crítica, no processo de sua formação, e que busque alternativas que permita a sua inserção no mercado de trabalho, formal ou informal, é que nosso projeto procura focalizar o empreendedorismo/profissionalização. Com o projeto, esperamos ampliar suas possibilidades de aprimoramento pessoal e profissional, para que ele tenha condições de uma sobrevivência digna e continue motivado a prosseguir seus estudos.

Atualmente o CEF 16 apresenta um alto índice de violência (criminal/civil); Violência doméstica; Tráfico de drogas; Desmotivação de professores; Falta de estrutura operacional na região; Mesma estrutura e padrão de aula; Falta de material didático especifico para EJA; os alunos apresentam grande desmotivação.

A compreensão da realidade local foi pré-requisito para aplicação da metodologia, o que foi colocado em prática por meio de observação, entrevista, correspondências e reuniões com os alunos.

Nessa perspectiva é que foi elaborado o PIL: O JOVEM/ADULTO TRABALHADOR E/OU EMPREENDEDOR NA EJA com a finalidade de estimular a capacidade criativa e promover reflexão sobre a realidade social na qual está inserido, o que deve gerar conscientização sobre o papel do próprio aluno como agente da transformação social. 
Compreendida como uma forma de organização social pautada pela solidariedade nas relações, em contraste com o individualismo.

a) Fatores sociais envolvidos no problema: comunidade carente (maioria é composta de carroceiros), baixa estima da comunidade, pois sofrem discriminação social;

b) Conflitos e/ou confrontos na localidade em função do problema: Sem uma educação de qualidade e uma perspectiva profissional perdem-se alunos para o tráfico.

c) Parceiros na busca de soluções: GDF, ONGs, escolas técnicas, institutos federais e a própria comunidade.

d) Políticas públicas voltadas para o problema identificado: urbanização de áreas públicas, instalação de postos policiais, oferta de cursos profissionalizantes, projetos culturais (dança, capoeira, teatro, esporte a meia-noite, etc.).

\section{JUSTIFICATIVA: MARCO CONCEITUAL - FUNDAMENTAÇÃO TEÓRICA}

A educação brasileira no contexto mundial apresenta a característica de formação geral do indivíduo, onde o desenvolvimento do educando tem de permear a concepção dos componentes científicos, tecnológicos, sócio-culturais e de linguagens. Além de que o indivíduo deve ter presente em todos os momentos de sua formação: o aprender a aprender e o aprender afazer.

A política educacional brasileira, a partir da homologação da Lei de Diretrizes e Bases (LDB) [1] preocupou-se com a preparação do educando para enfrentar os desafios de economias globalizadas e competitivas oferecendo uma educação geral e profissional com condições para superar esses obstáculos. A educação profissional transcende a fase do repetidor de processos para que promova a "transição entre escola e o mundo do trabalho, capacitando jovens e adultos com conhecimentos e habilidades gerais e específicas para $o$ exercício de atividades produtivas" [2].

Para efetivar essa política educacional, o Ministério da Educação (MEC) e o Serviço Brasileiro de Apoio às Micro e Pequenas Empresas (SEBRAE) desenvolve projetos em parceria para disseminação do empreendedorismo nas escolas de educação profissional, por meio de programas como: Programa Integrado MEC/SEBRAE de Técnicos Empreendedores, Programa Jovem Empreendedor, Programa Aprender a Empreender, entre outros.

Além de desenvolver esses projetos, preocupa-se com a visão do educador em relação a essa nova realidade da educação brasileira e para isso tem realizado projetos direcionados a esses educadores, afim de que possam difundir melhor essa cultura e através de sua prática pedagógica criar um contexto propício à efetivação desse projeto junto aos educandos 
Em geral a EJA recebe alunos de classe social com diversidade de valores socioculturais. Esse quadro reflete uma demanda desses sujeitos para o mercado de trabalho com o fim de satisfazer necessidades imediatas de sobrevivência. Como a oferta de empregos diminuiu a escolaridade já não garante uma boa colocação profissional; então, verifica-se desmotivação, evasão, descompromisso com o cotidiano escolar e, o mais grave, com a própria formação. O universo dos nossos alunos da EJA restringe-se a duas alternativas: estudar ou trabalhar. Por essa razão, nosso projeto procurará focalizar o empreendedorismo/profissionalização como visão de alternativas de sua inserção no mercado de trabalho, sem perder de vista o conhecimento que dará acesso a esse mundo. É significativa essa abordagem visto que o aluno perceberá a importância da sua formação escolar e se sentirá motivado a prosseguir seus estudos. Através de projetos interdisciplinares, o aluno poderá demonstrar a possibilidade de construir um currículo identificando-o com a sua realidade, estabelecendo a relação de sala de aula com uma sociedade mais ampla. $\mathrm{O}$ aluno escolhe o tema que mais se adéqua a situação vivenciada (trabalho, estudo, curso de formção, etc.). E com isso cada área de conhecimento montará o seu currículo, adequando o material pedagógico de suporte - que no momento não atende as necessidades reais dos alunos da EJA. Caberá a todas as áreas de conhecimentos a coordenação desse projeto a ser desenvolvido com todos os alunos dos vários segmentos. $A$ escolha se apóia nos princípios básicos do PROEJA e orientação da UNESCO para a formação humana para a vida e para o trabalho e também nos Parâmetros Curriculares Nacionais (PCN) e os Currículos Básicos Nacionais (CBC), segundo os quais se devem promover um ensino articulado com a realidade do aluno.

\section{OBJETIVOS}

Contratação/convênio de instituição de ensino particulares e/ou federais (IFB), atuantes na área da educação profissional de nível técnico, para prestação de serviços educacionais, na modalidade presencial, visando o incentivo, a participação, capacitação e formação profissional e inserção do aluno da EJA no mercado de trabalho.

\subsection{OBJETIVOS GERAIS}

Segundo Sonia Maria Portella Kruppa as relações entre educação e mundo do trabalho são hoje bastante complexas.

É pelo trabalho que os seres humanos transformam a natureza em meios de vida. Mas não fazem isso apenas de forma repetitiva. Ao transformar a natureza, homens e mulheres 
acumulam conhecimentos que, simultaneamente, mudam sua forma de produzir os meios de sua própria vida e sua relação com a natureza.

A educação, entendida como troca e diálogo entre e inter gerações, garante que homens e mulheres retransmitam esses conhecimentos uns aos outros. Com a constituição da escola, espaço destinado à transmissão de saberes. Ficam estabelecidas possibilidades de vinculação entre a educação escolar e o mundo do trabalho.

Ao longo de sua história, a escola tem assumido diferentes papéis, em relação ao mundo do trabalho, desde ser uma simples fornecedora de mão-de-obra adestrada a se tornar um espaço destinado à educação integral, ou, ainda, atendendo à montagem de um sistema dual de formação: o ensino profissionalizante aos menos favorecidos e o propedêutico às elites.

Portanto busca-se sensibilizar o aluno para a formação de si mesmo por meio de discussões sobre o seu papel social, em uma sociedade globalizada e competitiva.

\subsection{OBJETIVOS ESPECIFICOS}

- Programar uma prática pedagógica voltada para a formação do aluno empreendedor/trabalhador.

- Caracterizar o perfil do trabalhador no século XXI e analisar criticamente as políticas governamentais de emprego focadas na juventude.

- Ampliar a visão dos alunos acerca do mercado de trabalho.

- Familiarizar os alunos com as instituições de ensino superior e sua oferta de cursos.

- Estudar as profissões mais emergentes na sociedade brasileira e levar o aluno a ter uma visão mais objetiva sobre o mercado de trabalho.

- Estudar a importância da tecnologia no surgimento de novas profissões.

- Pesquisar junto ao SEBRAE possíveis ações capazes de aumentar a contribuição da educação escolar formal para a formação do jovem empreendedor/profissional.

- Promover palestras com os profissionais qualificados com foco nos fatores que interferem na escolha das profissões e no atual mercado de trabalho.

- Pesquisar junto ao SESI, SESC, SENAI e ESCOLAS TÉCNICAS e INSTITUTOS FEDERAIS ações para capacitação profissional e o envio destes para o mercado de trabalho.

- Contribuir para o sucesso pessoal e profissional do aluno.

- Retirar com os alunos temas para desenvolver os projetos pedagógicos interdisciplinares, com dinâmicas de leitura, uso da Internet, músicas, etc. 
- Usar a sala de Informática da escola para criação de Blogs, do site da escola e e-mails coletivos, etc., além de pesquisas sobre os temas.

\title{
6. ATIVIDADES/RESPONSABILIDADE
}

\author{
1aㅡ etapa:
}

Cursos oferecidos:

Sabão caseiro, sabão líquido, perfumes, sabonetes, desinfetantes, bonecas de pano, almofadas, bolsas, etc. - Ministradores: alunos da comunidade. Professores responsáveis: Química, Física, Matemática e Arte.

2a etapa:

Cursos oferecidos:

Controle de estoque, Técnicas de vendas, Cerimonial e protocolo, Recepção e hotelaria, Sondador de solo, Web design.

\section{CRONOGRAMA}

- Discussão sobre a metodologia do projeto e levantamento de dados bibliográficos, pesquisa e seleção de material para fundamentação teórica.

- Reunião para apresentação e entrega do material pesquisado, exposição e trocas sobre as leituras feitas.

- $\quad$ Elaboração de cronograma para o desenvolvimento do projeto.

- Apresentação aos alunos da proposta a ser desenvolvida e levantamento de suas sugestões para o enriquecimento do projeto.

- Aplicação de questionários para levantamento das áreas de interesse profissional dos alunos.

- Promoção de uma palestra sobre mercado de trabalho.

- Pesquisa e montagem de portfólios sobre mercado de trabalho informal.

- Encontro do grupo para avaliação do trabalho do projeto e possíveis trocas e ajustes.

- Escolha de temas a serem adequados ao currículo em sala de aula.

- Seminário de aprofundamento dos temas pesquisados. 
- Preparação de roteiro das atividades a serem realizadas durante os trabalhos de campo.

- Trabalhos de campo, com desenvolvimento do(s) tema(s) escolhido(s).

- Realização de oficinas para ampliar a visão dos alunos acerca de iniciativas empreendedoras.

- Fazer uso dos suportes textuais, internet, rádio e TV para pesquisas e como fazer desses suportes instrumentos importantes na aprendizagem diária.

- Refletir sobre o uso dessas tecnologias na vida cotidiana.

- Inscrição para os cursos oferecidos.

- Efetivação de matrículas.

- Montagem das turmas e início dos cursos.

- Mostra Cultural - apresentação dos trabalhos desenvolvidos durante o período/formatura do aluno.

\section{PARCEIROS}

O presente projeto visa trabalhar em parceria com a Secretaria de Educação, Secretaria de Ciência e Tecnologia, Escolas Técnicas, Institutos Federais, ONGs e a própria comunidade escolar.

\section{ORÇAMENTO}

O custo inicial é de aproximadamente $R \$ 500,00$ (Quinhentos Reais), para comprar materiais para a confecção de velas artesanais, sabão caseiro, sabão líquido, perfumes, sabonetes, desinfetantes, bonecas de pano, almofadas, bolsas, etc.

\section{ACOMPANHAMENTO E AVALIAÇÃO}

Os cursos serão ministrados pelos próprios alunos/comunidade com acompanhamento de professores de Física, Química, Matemática e Arte. A avaliação dos trabalhos finais será feita pela equipe de professores em geral.

\section{RELATÓRIO DE EXPERIÊNCIA}

O relatório de experiência será feito através de um questionário sócio-participativo aplicado na instituição educacional na qual o projeto foi implantado, visando avaliar as mudanças significativas na vida escolar/profissional do aluno e da comunidade.

O relatório deverá conter todos os itens relatados do documento base de orientação para o PIL (letras de "A - I"). 


\section{REFERÊNCIAS}

ANTUNES, Ricardo. Os sentidos do trabalho: ensaio sobre a afirmação e a negação do trabalho. São Paulo: Boitempo, 1999.

ARANHA, A. V. S.. Relação entre o Conhecimento Escolar e o Conhecimento Produzido no Trabalho: dilemas da educação do adulto trabalhador. Trabalho e Educação, Belo Horizonte, v. 12, n. 1, p. 103-114, 2003.

Educação profissional: mudanças no mundo do trabalho, intervenção do BM, sistema de ensino. Belo Horizonte: UFMG, 2007. Notas de textos de aula. ARROYO, Miguel G Educação de Jovens e Adultos - um campo de direitos e de responsabilidade pública in: SOARES, L. et ali (orgs.) Diálogos na educação de jovens e adultos. Belo Horizonte: Autêntica, 2005.

ARROYO, Miguel. Questões teóricas-práticas na Educação Profissional Integrada à EJA: do chão da escola à literatura. Belo Horizonte: CEFET/MG. Palestra proferida no II Seminário de EPIEJA, em Belo Horizonte, em 30/11/2007.

ARROYO, Miguel. Trabalho - Educação e Teoria Pedagógica. In FRIGOTTO, Gaudêncio (Org.). Educação e crise no trabalho: perspectivas de final de século. 6 ed. Petrópolis: Vozes, 2001.

Educação de Jovens Adultos: um campo de direitos e de responsabilidade pública. In: Diálogos na educação de jovens e adultos (org.) Soares, Leôncio. Belo Horizonte: Autêntica, 2005.

BRASIL. Decreto n. 5478, de 24 de junho de 2005. Institui, no âmbito das instituições federais de educação tecnológica, o Programa de Integração da Educação Profissional ao Ensino Médio na Modalidade de Educação de Jovens e Adultos (PROEJA). Brasília, DF, 2005.

BRASIL. Lei no 9.394, de 20 de dezembro de 1996. Estabelece as diretrizes e bases da educação nacional. São Paulo: Editora do Brasil S/A, 1996.

CUNHA, Luiz Antônio. O ensino profissional na irradiação do industrial ismo. Brasília: UNESP, 2005.

Declaração de Hamburgo sobre Educação de Adultos; Agenda para o futuro da educação de Adultos. V Conferência Internacional sobre Educação de Adultos V CONFINTEA Julho 1997: Disponível em: http://www.fe.unicamp.br/gepeja/arquivos/VConfintea.pdf

DORNELAS, J. C. A. Empreendedorismo - Transformando idéias em negócios. Rio de janeiro: Campus, 2001.

FREIRE, Paulo. Pedagogia do Oprimido. Rio de Janeiro: Paz e Terra, 2005.

FRIGOTTO, Gaudêncio (org.). Educação e Crise do trabalho: perspectives de final de século. Petrópolis, RJ: Vozes, 1998. 
GRAMSCI. Antônio. Os intelectuais e a organização da cultura. Rio de janeiro: Civilização Brasileira, 1995.

KRUPPA, Sonia M. Portella. Sociologia da Educação. São Paulo, Cortez: 1994.

KUENZER, Acácia Zeneida. O ensino médio agora é para a vida: Entre o pretendido, o dito e o feito. In: Educação e Sociedade. V.21, n. 70. Campinas, abril. 2000.

LEVENFUS, Rosane S. et al. Psicodinâmica da escolha profissional. Porto Alegre: Artes Médicas, 1997.

MANACORDA, Mário A. O princípio educativo em Gramsci. Porto Alegre: Artes Médicas, 1990.

MANFREDI, Silvia. Educação Profissional no Brasil. São Paulo: Cortez, 2002.

MARX, K.; ENGELS, F. Obras escolhidas, vol. 1,Rio de Janeiro: Vitória, s/d Marília

MAUÊS, O. C.; GOMES, E.; MENDONÇA, F. L. Políticas para a Educação Profissional Média dos anos 1997-2007. In: revista do NETE. Belo Horizonte: Faculdade de Educação da UFMG. Núcleo de Estudos sobre trabalho \& Educação. V.17, n.1. jan/abr. 2008. p.109-122.

MAUÈS, Olgaíses. Os organismos internacionais e as políticas públicas educacionais no Brasil. In: Currículo e Políticas Públicas. Gonçalves (org.). Belo Horizonte: Autênticas, 2003.

NOSELLA, Paolo. Trabalho e perspectivas de formação dos trabalhadores: para além da formação politécnica. Revista Brasileira de Educação. v.12 n.34. Rio de Janeiro, jan./abr. 2007.

PISTRAK. Fundamentos da escola do trabalho. São Paulo: Expressão Popular, 2000.

SANTOS, Boaventura S. Pela mão de Alice: o social e o político na pósmodernidade $4 .^{a}$ ed. São Paulo : Cortez, 1997.

SANTOS, Eloísa Helena. Processos de produção e legitimação de saberes no trabalho. In: Currículo e Políticas Públicas. Gonçalves (org.). Belo Horizonte: Autênticas, 2003.

SAVIANI, Dermeval. O trabalho como principio educativo: as novas tecnologias. In: Tecnologias, Trabalho e educação: um debate multidisciplinar. Petrópolis, RJ: Vozes, 1994.

SERVIÇO BRASILEIRO DE APOIO AS MICO E PEQUENAS EMPRESAS. Disponível em $<H T T P: / /$ WWW.sebrae.com.br> Acessado em 26/06/2010.

WERMELINGER, M; MACHADO, M. H.; AMÂNCIO FILHO, A. Políticas de educação profissional: referências e perspectivas. In: Ensaio: avaliação, política. Educação. Rio de Janeiro, v. 15, n. 55, abr./jun. 2007 


\subsection{ANEXOS}

\section{Cursos de Qualificação}

\section{CONTROLE DE ESTOQUE}

O Curso de Controle de Estoque tem como objetivo capacitar o aluno para o conhecimento das competências e habilidades necessárias à administração de materiais, habilitando-o a ingressar no mercado de trabalho como almoxarife, estoquista, auxiliar de estoque e em atividades similares, além de atualizar aqueles que já atuam na área de almoxarifado ou controle de estoque e necessitam de aperfeiçoamento profissional para um melhor desempenho de suas atividades.

Durante o curso o estudante aprenderá métodos de planejamento, organização e controle de estoques, noções básicas de administração, redação técnica e informática básica.

Carga-horária: 160 horas

Turno: Vespertino e Noturno

Período: três meses

Pré-requisitos: Ensino fundamental completo e idade mínima de 16 anos

Campus Responsável: Brasília e Taguatinga

Local: Escola São Francisco - São Sebastião; Centro Educacional Gisno - Asa Norte e Centro Educacional 07 - Taguatinga.

\section{TÉCNICAS DE VENDAS E PÓS-VENDAS}

O Curso de Técnicas de Vendas e Pós-Vendas tem como objetivo capacitar o aluno para o conhecimento de competências e habilidades necessárias em vendas e pós-vendas, habilitando-o a ingressar no mercado de trabalho como vendedor, demonstrador, representante comercial e em atividades similares, além de atualizar profissionais que já atuam no setor de comércio e necessitam de aperfeiçoamento profissional para um melhor desempenho em suas atividades. 
Durante o curso o estudante aprenderá noções de planejamento, organização e controle de vendas e pós-vendas, noções básicas de administração, redação técnica e informática básica.

Carga-horária: 160 horas

Turno: Vespertino e Noturno

Período: três meses

Pré-requisitos: Ensino fundamental completo e idade mínima de 16 anos

Campus Responsável: Brasília e Taguatinga

Local: Escola São Francisco - São Sebastião; Centro Educacional Gisno - Asa Norte e Centro Educacional 07 - Taguatinga.

\section{CERIMONIAL E PROTOCOLO}

O Curso de Cerimonial e Protocolo tem como objetivo capacitar o aluno para o conhecimento das competências necessárias à prática do Cerimonial e Protocolo de Eventos. Esse profissional auxilia na realização dos diversos tipos de eventos como casamento, conferências, palestras, dentre outros.

Durante o curso o estudante aprenderá técnicas de oratória, regras de etiqueta, noções de informática e redação técnica.

Carga-horária: 160 horas

Turno: Vespertino e Noturno

Período: três meses

Pré-requisitos: Ensino fundamental completo e idade mínima de 16 anos

Campus Responsável: Brasília e Taguatinga

Local: Escola São Francisco - São Sebastião; Centro Educacional Gisno - Asa Norte e Centro Educacional 07 - Taguatinga. 


\section{RECEPÇÃO HOTELARIA}

O Curso de Recepção Hoteleira tem como objetivo capacitar o aluno para o conhecimento das competências necessárias à recepção hoteleira. Esse profissional é preparado para auxiliar no recebimento de hóspedes, atividades de check-in, check-out, preenchimento de ficha cadastral, dentre outras.

Durante o curso o estudante aprenderá técnicas de comunicação, hospitalidade, etiqueta, noções básicas de administração hoteleira, turismo, informática e segurança no trabalho.

Carga-horária: 160 horas

Turno: Vespertino

Período: três meses

Pré-requisitos: Ensino fundamental completo e idade mínima de 16 anos

Campus Responsável: Brasília

Local: Centro Educacional Gisno - Asa Norte.

\section{SONDADOR DE SOLO}

O Curso de Sondador de Solo destina-se à formação de profissionais para atuar na sondagem de solos e rochas, por meio de perfurações a trado, SPT, rotativa e outros. O aluno aprenderá ainda a fazer a identificação dos solos, ensaios de permeabilidade e infiltração.

Carga-horária: 205 horas

Turno: Noturno

Período: três meses

Pré-requisitos: Ensino fundamental completo e idade mínima de 16 anos

Campus Responsável: Samambaia

Local: SEPN 504 Bloco A 3ํo andar, Edifício Ana Carolina. 


\section{WEB DESIGN}

O Curso de Web Design tem como objetivo capacitar o aluno para criar layouts, definir identidade visual de sites e programar websites. $\mathrm{O}$ estudante desenvolverá habilidades e competências para desenvolver interfaces gráficas com imagens, combinação de cores, formas e fontes.

Carga-horária: 200 horas

Turno: Vespertino

Período: três meses

Pré-requisitos: Ensino fundamental completo, conhecimento básico de informática (sistema operacional gráfico e editor de texto)

Campus Responsável: Taguatinga

Local: Campus Taguatinga. 